\title{
La subasta de medicamentos en Andalucía. Cuestiones controvertidas y perspectivas de futuro
}

\author{
The auction of medicines in Andalucía. \\ Controversial issues and future prospects
}

\author{
Elsa Marina Álvarez González \\ Universidad de Málaga \\ emalvarez@uma.es
}

\section{RESUMEN}

El procedimiento de subasta de medicamentos establecido en la Comunidad Autónoma de Andalucía en el año 2011 como medida de ahorro del gasto farmacéutico ha sido duramente criticado tanto por el Gobierno de la nación que ha interpuestos varios recursos ante el TC por invasión competencial, como por los laboratorios farmacéuticos españoles cuyos intereses se han visto duramente perjudicados con el sistema andaluz. Sin embargo, el TC ha venido a avalar la constitucionalidad de la medida y parece que las últimas noticias apuntan a que se pueda convertir en una medida modelo para el resto de Comunidades Autónomas. De ahí, el interés en realizar este análisis jurídico sobre un tema de máxima actualidad y poder identificar los pros y contras de esta medida andaluza que si bien surge con un carácter claramente coyuntural -motivado por la crisis económica-, su reciente respaldo por el TC podría convertirla en una medida estructural en la dispensación de la prestación farmacéutica en nuestro país.

\section{PALABRAS CLAVE}

Prestación farmacéutica, selección de medicamentos, subasta de medicamentos.

\begin{abstract}
In 2011 the Andalusian Government established a procedure of acquiring medicines through auction as a measure to control the pharmaceutical expense. This action has been harshly criticised by both the Spanish Central Government and the pharmaceutical companies since their interests have been seriously affected. However, the Spanish Constitutional Court has approved this system as constitutional thus, other regional governments may adopt it as well. Therefore, it seems necessary to examine this matter from a legal point of view since, although it started as a temporary measure due to the recession, it may become a regular practice of public distribution of medicines in Spain.
\end{abstract}

\section{KEYWORDS}

Pharmaceutical supply, procedure of acquiring medicines, medicines auction.

\section{SUMARIO}

1. INTRODUCCIÓN. 2. PRINCIPIOS GENERALES QUE RIGEN LA SELECCIÓN DE MEDICAMENTOS EN ANDALUCÍA. 3. EL PROCEDIMIENTO DE SUBASTA DE MEDICAMENTOS EN LA LEY DE FARMACIA DE ANDALUCÍA. 4. CUESTIONES CONTROVERTIDAS DEL PROCEDIMIENTO DE SUBASTA DE MEDICAMENTOS EN ANDALUCÍA. 4.1. APLICABILIDAD DE LA LEGISLACIÓN DE CONTRATOS DEL 
SECTOR PÚBLICO AL PROCEDIMIENTO DE SUBASTA DE MEDICAMENTOS. 4.2. INFRACCIÓN DE LA LEY 20/2013, DE 9 DE DICIEMBRE, DE GARANTÍA DE LA UNIDAD DE MERCADO. 4.3. VULNERACIÓN DE LAS COMPETENCIAS EXCLUSIVAS DEL ESTADO PARA GARANTIZAR LA IGUALDAD DE TODOS LOS CIUDADANOS (149.1.1 CE) Y EN MATERIA DE BASES Y COORDINACIÓN GENERAL DE LA SANIDAD Y LEGISLACIÓN SOBRE PRODUCTOS FARMACÉUTICOS (ART. 149.1.16 CE). 4.4. UN APUNTE DE FUTURO SOBRE LAS SUBASTAS DE MEDICAMENTOS. 5. BIBLIOGRAFÍA.

\section{INTRODUCCIÓN}

Como es sabido, la crisis económica que hemos vivido en los últimos años ha obligado a los poderes públicos a adoptar toda una serie de medidas de distinto alcance para paliar los efectos económicos de la crisis. Uno de los sectores más afectados ha sido la sanidad pública donde había que reducir el gasto sanitario a toda costa. En este contexto, la Comunidad Autónoma andaluza decidió en el año 2011 diseñar un procedimiento muy singular para la selección de los medicamentos que se dispensan en las oficinas de farmacia. Acudió así a la celebración de subastas para adjudicar por precio a los laboratorios farmacéuticos en exclusiva los medicamentos que se iban a dispensar obligatoriamente en todas las oficinas de farmacia del sistema sanitario público andaluz.

Este sistema de subasta de medicamentos, pionero en Andalucía, pronto se ganó el rechazo tanto del gobierno central como de los laboratorios farmacéuticos que veían en él la vulneración del principio de igualdad de trato y la conculcación de las competencias estatales. A este debate jurídico han puesto fin las sentencias 210/2016, de 15 de diciembre y 7/2017, de 19 de enero del TC que resuelven los diferentes procedimientos judiciales planteados ante él y en las que el Alto Tribunal salva la constitucionalidad del procedimiento de subasta andaluz. No obstante, creemos que las cuestiones jurídicas planteadas son de enorme calado y tanto el procedimiento andaluz como los argumentos esgrimidos por el TC, así como el devenir futuro en este tema, merecen un análisis en profundidad.

\section{PRINCIPIOS GENERALES QUE RIGEN LA SELECCIÓN DE MEDICAMENTOS EN ANDALUCÍA}

La prestación farmacéutica del sistema sanitario público de Andalucía comprende todos aquellos medicamentos y productos sanitarios incluidos en la prestación farmacéutica del Sistema Nacional de Salud o por decisión del Consejo de Gobierno de la Junta de Andalucía (con cargo a sus propios presupuestos y en las condiciones que se determine ${ }^{1}$ ) destinados a que los pacientes los reciban y utilicen de forma adecuada a sus necesidades clínicas. Pero también, los que se adquieran para ser utilizados en los centros sanitarios públicos de acuerdo con los criterios de selección determinados por la Comisión Multidisciplinar de Uso Racional del Medicamento correspondiente; los que cuenten con autorización expresa para uso compasivo por el Ministerio de Sanidad; ó los que sean autorizados por el órgano correspondiente del Ministerio de Sanidad exclusivamente para un ensayo clínico, cuando este sea promovido por un centro sanitario del sistema sanitario público de Andalucía ${ }^{2}$. Por tanto, comprende, tal y como establece el art. 16 de la Ley16/2003, de 28 de mayo, de Cohesión y Calidad del Sistema Nacional de Salud, al regular la prestación farmacéutica con carácter general, los medicamentos y productos sanitarios y el conjunto de actuaciones encaminadas a que los pacientes los reciban de forma adecuada a sus necesidades clínicas, en las dosis precisas según sus requerimientos individuales, durante el período de tiempo adecuado y al menor coste posible para ellos y la comunidad ${ }^{3}$.

La prestación farmacéutica entendida, pues, como un servicio sanitario que satisface el derecho a la protección de la salud reconocido en el art 43 de la $\mathrm{CE}^{4}$-así como en el art. 22.1 del EAA- se materializa a

\footnotetext{
1 Véase al respecto el Decreto 159/1998, de 28 de julio, por el que se regula la prestación de determinados medicamentos con cargo a fondos propios de la Comunidad Autónoma.

2 Según el art. 59 Ley 22/2007, de 18 de diciembre, de Farmacia de Andalucía.

3 En el mismo sentido se recoge en la Exposición de Motivos del Real Decreto Legislativo 1/2015, de 24 de julio, por el que se aprueba el texto refundido de la Ley de garantías y uso racional de los medicamentos y productos sanitarios.

4 En el mismo sentido, BOMBILLAR SÁENZ, F., Intervención administrativa y régimen jurídico del medicamento en la Unión Europea, Ed. UGR, 2010, pág. 557, que establece que los medicamentos son bienes económicos a través de los cuales se hace efectivo el derecho a la protección de la salud consagrado en el art. 43CE, pues contribuyen a prevenir, curar o aliviar enfermedades y a corregir o reparar las secuelas provocadas por éstas.
} 
través de la selección, prescripción, dispensación y administración de medicamentos y productos sanitarios a los ciudadanos. Así, el art. 91 Real Decreto Legislativo 1/2015, de 24 de julio, por el que se aprueba el texto refundido de la Ley de garantías y uso racional de los medicamentos y productos sanitarios (en adelante, TRLGURM) reconoce el derecho de todos los ciudadanos a obtener medicamentos en condiciones de igualdad en todo el Sistema Nacional de Salud, sin perjuicio de las medidas tendentes a racionalizar la prescripción y la utilización de medicamentos y productos sanitarios que puedan adoptar las comunidades autónomas en ejercicio de sus competencias. Por tanto, estamos ante una prestación sanitaria que, a pesar de sus singulares características, pues se trata de un servicio público de interés general prestado de forma privada $^{5}$, se encuentra regulada e intervenida por la Administración pública para garantizar tanto la seguridad y calidad de los medicamentos como el acceso de los ciudadanos a los mismos ${ }^{6}$.

La prestación farmacéutica responde en nuestros días a un principio básico y esencial como es el uso racional de los medicamentos introducido por la Ley del Medicamento de 1990. Ello justifica la regulación de las distintas actuaciones que garantizan el derecho a los medicamentos de los ciudadanos (selección, preinscripción, dispensación y administración), así como su financiación pública. Y esa regulación se realiza, a día de hoy, en el TRLGURM (de ámbito estatal) ${ }^{7}$ y, en el ámbito andaluz, en la Ley de Farmacia de Andalucía (Ley 22/2007, de 18 de diciembre, en adelante, LFA). En ella, el Título III se dedica al uso racional de los medicamentos y somete la prescripción, dispensación y administración de medicamentos, con la finalidad de garantizar a los pacientes el adecuado nivel de seguridad y eficacia, a los siguientes principios generales (art. 58):

a) Sólo se pueden prescribir medicamentos legalmente reconocidos y, exclusivamente, para las indicaciones contenidas en las correspondientes autorizaciones, incluidas las de tratamientos compasivos y ensayos clínicos.

b) El profesional que realiza la prescripción debe informar adecuadamente al paciente sobre las características del tratamiento prescrito, así como sobre la correcta administración de los medicamentos indicados.

c) El farmacéutico dispensará los medicamentos y productos sanitarios que se le soliciten, en las condiciones legal y reglamentariamente establecidas.

d) El farmacéutico velará por el cumplimiento de las pautas establecidas por el médico responsable del paciente en la prescripción, informando al paciente sobre las condiciones de conservación, preparación, administración y posología de los medicamentos dispensados.

e) El farmacéutico en el acto de la dispensación de medicamentos y productos sanitarios está obligado a cumplir las prescripciones económicas y administrativas que determine la normativa reguladora de la dispensación de medicamentos y, en su caso, de productos sanitarios.

Además, el Estado en ejercicio de su competencia exclusiva en materia de legislación sobre productos farmacéuticos ha establecido en el art. 87 del TRLGURM de 2015 -al igual que hiciera el antiguo art. 85 de la Ley 29/2006, de 26 de julio- que la prescripción de medicamentos y productos sanitarios en el Sistema Nacional de Salud se efectuará en la forma más apropiada para el beneficio de los pacientes, a la vez que se protege la sostenibilidad del sistema. Por ello, en el Sistema Nacional de Salud, las prescripciones de medicamentos incluidos en el sistema de precios de referencia o de agrupaciones homogéneas no incluidas en el mismo, se efectuarán de acuerdo con el siguiente esquema:

a) Para procesos agudos, la prescripción se hará, de forma general, por principio activo.

b) Para los procesos crónicos, la primera prescripción, correspondiente a la instauración del primer tratamiento, se hará, de forma general, por principio activo.

\footnotetext{
5 Véase el análisis de los distintos elementos que configuran la naturaleza jurídica de la prestación farmacéutica que realizamos en nuestro trabajo "La ordenación farmacéutica en Andalucía" en PÉREZ MONGUIO, J. M. y FERNÁNDEZ RAMOS, S. (dirs.) EI Derecho de Salud Pública y Políticas Sociales e Igualdad en Andalucía, Ed. IAAP, 2016, págs. 193 a 203.

' Así lo establece VIDA FERNANDEZ, J., "La prestación farmacéutica como subsistema prestacional sanitario" en MONEREO PÉREZ, J. L., Comentarios a la legislación reguladora de la sanidad en España. Régimen jurídico de la organización sanitaria, personal sanitario y prestaciones sanitarias, Ed. Comares, 2007, págs. 297 a 342.

7 Que ha venido a derogar la anterior Ley 29/2006, de 26 de julio, de garantías y uso racional de los medicamentos y productos sanitarios.
} 
c) Para los procesos crónicos cuya prescripción se corresponda con la continuidad de tratamiento, podrá realizarse por denominación comercial, siempre y cuando ésta se encuentre incluida en el sistema de precios de referencia o sea la de menor precio dentro de su agrupación homogénea.

Ahora bien, cuando la prescripción se realice por principio activo, el farmacéutico dispensará el medicamento de precio más bajo de su agrupación homogénea. Aquí radica la mayor novedad con respecto a la regulación anterior, pues el art. 85.4 de la Ley 29/2006, de 26 de julio, establecía que «Cuando la prescripción se realiza por principio activo, el farmacéutico dispensará el medicamento de precio más bajo de su agrupación homogénea y, en el caso de igualdad, el medicamento genérico o el medicamento biosimilar correspondiente». Modificación, además, muy significativa en la argumentación del TC en la sentencia $210 / 2016$ que resuelve el recurso de inconstitucionalidad frente a la subasta de medicamentos, como veremos más adelante.

Por tanto, se establece, como regla general, la prescripción de los medicamentos por principio activo8 (identificando el fármaco con la Denominación Común Internacional $(\mathrm{DCl})$ o, en su caso, a través de la Denominación Oficial Española (DOE) en lugar de por el nombre comercial), debiendo el farmacéutico dispensar el medicamento de menor precio. De esta forma se favorece el uso racional de los medicamentos dispensando siempre los medicamentos de menor coste. Pero téngase en cuenta que ya no se favorece la dispensación de medicamentos genéricos ${ }^{9}$ que había venido rigiendo la dispensación en la prescripción por principio activo desde que se aprobó el Real Decreto-ley 16/2012, de 20 de abril, de medidas urgentes para garantizar la sostenibilidad del Sistema Nacional de Salud y mejorar la calidad y seguridad de sus prestaciones, y que modificó el art. 85 de la anterior Ley 29/2006, de 26 de julio, para establecer que en caso de igualdad de precios, el farmacéutico debía dispensar el medicamento genérico. Ahora, en caso de prescripción por principio activo, siempre que el medicamento se encuentre al precio más bajo de su agrupación homogénea, se puede dispensar indistintamente el genérico o el de marca.

Estos requisitos que impone el legislador estatal para la prescripción y dispensación de los medicamentos han sido recogidos también en el ámbito del sistema sanitario público de Andalucía ${ }^{10}$. En este sentido, la LFA establece que la prescripción y dispensación de medicamentos y productos sanitarios se realizará en la receta médica o en la orden de dispensación y, en todo caso, con el menor coste posible en las correspondientes dispensaciones (art. 60.2). Y para garantizar ese menor coste del medicamente regula un sistema de selección de los medicamentos a dispensar cuando se prescriban o indiquen por principio activo y de los productos sanitarios a dispensar cuando se prescriban por denominación genérica, a través de un procedimiento de subasta en el que podrán participar todos los laboratorios farmacéuticos interesados, para seleccionar, de entre los medicamentos comercializados que tengan un precio autorizado igual o inferior al precio menor correspondiente, establecido en el SNS y vigente en el momento de la convocatoria, aquél que deberá ser dispensado por las oficinas de farmacia en Andalucía.

\footnotetext{
8 Por «principio activo» o "sustancia activa» se entiende toda sustancia o mezcla de sustancias destinadas a la fabricación de un medicamento y que, al ser utilizadas en su producción, se convierten en un componente activo de dicho medicamento destinado a ejercer una acción farmacológica, inmunológica o metabólica con el fin de restaurar, corregir o modificar las funciones fisiológicas, o de establecer un diagnóstico. Según se recoge en el art. 8.c) de la Ley 29/2006, de 26 de julio, de garantías y uso racional de los medicamentos y productos sanitarios redactado por el apartado seis del artículo único de la Ley 10/2013, de 24 de julio, por la que se incorporan al ordenamiento jurídico español las Directivas 2010/84/UE del Parlamento Europeo y del Consejo, de 15 de diciembre de 2010, sobre farmacovigilancia, y 2011/62/UE del Parlamento Europeo y del Consejo, de 8 de junio de 2011, sobre prevención de la entrada de medicamentos falsificados en la cadena de suministro legal.

9 Entendemos por medicamento genérico: «Todo medicamento que tenga la misma composición cualitativa y cuantitativa en principios activos y la misma forma farmacéutica, y cuya bioequivalencia con el medicamento de referencia haya sido demostrada por estudios adecuados de biodisponibilidad. Las diferentes sales, ésteres, éteres, isómeros, mezclas de isómeros, complejos o derivados de un principio activo se considerarán un mismo principio activo, a menos que tengan propiedades considerablemente diferentes en cuanto a seguridad y/o eficacia. Las diferentes formas farmacéuticas orales de liberación inmediata se considerarán una misma forma farmacéutica. El solicitante podrá estar exento de presentar los estudios de biodisponibilidad si puede demostrar que el medicamento genérico satisface los criterios pertinentes definidos en las correspondientes directrices detalladas» (art. 2.g) TRLGURM).

10 En efecto, el art. 60 de la LFA establece: «1. En el ámbito del Sistema Sanitario Público de Andalucía, la prescripción, indicación o autorización de dispensación de los medicamentos y de los productos sanitarios, comprendidos en su prestación farmacéutica, se realizará en la receta médica o en la orden de dispensación, en los términos previstos en la Ley 29/2006, de 26 de julio, de garantías y uso racional de los medicamentos y productos sanitarios. 2. La dispensación de recetas médicas y órdenes de dispensación de medicamentos y productos sanitarios, se efectuará de acuerdo con lo dispuesto en los arts. 85.1 y 86 de la Ley 29/2006, de 26 de julio, de garantías y uso racional de los medicamentos y productos sanitarios». Las referencias a la Ley 29/2006, de 26 de julio, tenemos que entenderlas referidas a los artículos correspondientes del TRLGURM de 2015, tal y como establece en la Disposición adicional única del mismo.
} 
Por último, el principio de uso racional de los medicamentos se concreta no sólo con criterios de racionalidad sino también con criterios de contención del gasto público ${ }^{11}$. De ahí, el sistema de financiación pública de los medicamentos establecido por el Estado para fijar y controlar los precios de los mismos bajo criterios de uso racional ${ }^{12}$. Así, se regula tanto la financiación de los medicamentos (financiación selectiva, copago y los precios de referencia) como su dimensión económica fijando el precio industrial y los márgenes comerciales $^{13}$.

En efecto, para que un medicamento o producto sanitario se financie públicamente será necesaria su inclusión en la prestación farmacéutica mediante la correspondiente resolución expresa de la unidad responsable del Ministerio de Sanidad, Servicios Sociales e Igualdad, estableciendo las condiciones de financiación y precio en el ámbito del SNS. Y ello se posibilita mediante la financiación selectiva y no indiscriminada teniendo en cuenta criterios generales, objetivos y publicados y, concretamente, los siguientes (art.92.1 TRLGURM):

a) Gravedad, duración y secuelas de las distintas patologías para las que resulten indicados.

b) Necesidades específicas de ciertos colectivos.

c) Valor terapéutico y social del medicamento y beneficio clínico incremental del mismo teniendo en cuenta su relación coste-efectividad.

d) Racionalización del gasto público destinado a prestación farmacéutica e impacto presupuestario en el Sistema Nacional de Salud.

e) Existencia de medicamentos u otras alternativas terapéuticas para las mismas afecciones a menor precio o inferior coste de tratamiento.

f) Grado de innovación del medicamento.

No obstante, no se incluyen en la prestación farmacéutica medicamentos no sujetos a prescripción médica, medicamentos que no se utilicen para el tratamiento de una patología claramente determinada, ni los productos de utilización cosmética, dietéticos, aguas minerales, elixires, dentífricos y otros productos similares. Tampoco se financian los medicamentos indicados en el tratamiento de síndromes y/o síntomas de gravedad menor, ni aquellos que, aun habiendo sido autorizados de acuerdo a la normativa vigente en su momento, no respondan a las necesidades terapéuticas actuales, entendiendo por tal un balance beneficio/ riesgo desfavorable en las enfermedades para las que estén indicados.

Corresponde al Gobierno revisar periódicamente y actualizar la relación de los medicamentos y productos sanitarios incluidos en la prestación farmacéutica del SNS, de acuerdo con la evolución de los criterios de uso racional, los conocimientos científicos, la aparición de nuevos medicamentos de mayor utilidad terapéutica o la aparición de efectos adversos que hagan variar la relación beneficio/riesgo y los criterios que hemos señalado anteriormente. Para la decisión de financiación de nuevos medicamentos, además del correspondiente análisis coste-efectividad y de impacto presupuestario, se tendrá en cuenta el componente de innovación, para avances terapéuticos indiscutibles por modificar el curso de la enfermedad o mejorar el curso de la misma, el pronóstico y el resultado terapéutico de la intervención y su contribución a la sostenibilidad del SNS si, para un mismo resultado en salud, contribuye positivamente al Producto Interior Bruto.

Pero además, corresponde al Gobierno establecer los criterios y el procedimiento para la fijación del precio de los medicamentos y productos sanitarios financiables por el SNS (art. 94 TRLGURM). Como regla general, el precio de financiación será inferior o igual al precio industrial del medicamento aplicado cuando sea dispensado fuera del SNS. Los laboratorios farmacéuticos, las entidades de distribución y las oficinas de farmacia a través de la Organización Farmacéutica Colegial, deben aportar la información necesaria para hacer efectivo el reembolso debido por las oficinas de farmacia a laboratorios farmacéuticos y entidades de distribución en aquellos medicamentos que hayan sido dispensados fuera del SNS. En cualquier caso, es

11 Sobre el gasto farmacéutico, son muy interesantes los datos que se presentan en el estudio "El gasto farmacéutico en España en 2016. Evolución internacional y situación desde el punto de vista nacional", elaborado por EAE Business School (http://static.correofarmaceutico.com/docs/2016/09/05/gasto-farmaceutico-2016.pdf). Véase también TAMAYO LORENZO, P. A., "El gasto farmacéutico y la industria" en GIMENO ULLASTRES, J. A. (dir.), Economía de la Salud: Fundamentos, Ed. Díaz de Santos, 2013. págs. 245 y ss.

12 MUÑOZ MACHADO, S., "Gasto farmacéutico y otras reformas del SNS", Revista Derecho y Salud, vol. 9, núm. 2, 2001.

13 Véase ALEGRE PÉREZ, E. y LASTRES GARCÍA, J. L., Normativa legal sobre las especialidades farmacéuticas publicitarias en España y su situación en el entorno europeo, Universidad Complutense de Madrid, Madrid, 2003; VIDA FERNÁNDEZ, J. "Precio y financiación de los medicamentos" en Curso básico de derecho farmaceútico: 100 cuestiones esenciales, Asociación Española de Derecho Farmacéutico, Madrid, 2005 pág. 171 y ss. 
el Ministerio de Sanidad, Servicios Sociales e Igualdad el que establece el precio de venta al público de los medicamentos y productos sanitarios financiados mediante la agregación del precio industrial autorizado, que tiene carácter de máximo, y de los márgenes correspondientes a las actividades de distribución mayorista y dispensación al público.

Este sistema de financiación pública de medicamentos está sometido, por último, a un sistema de precios de referencia regulado en el art. 98 del TRLGURM ${ }^{14}$. El precio de referencia es la cuantía máxima con la que se financian las presentaciones de medicamentos incluidas en cada uno de los conjuntos que se determinen, siempre que se prescriban y dispensen con cargo a fondos públicos ${ }^{15}$. El precio de referencia de cada conjunto se calcula en base al coste/tratamiento/día menor de las presentaciones de medicamentos en él agrupadas y, en todo caso, deberá garantizarse el abastecimiento a las oficinas de farmacia para los medicamentos de precio menor. Los medicamentos no podrán superar el precio de referencia del conjunto al que pertenezcan. Los precios de los conjuntos ya existentes se revisan con carácter anual. No obstante, los precios menores de las nuevas agrupaciones homogéneas serán fijados, automáticamente, en el Nomenclátor que corresponda, y los precios menores de las ya existentes serán revisados con carácter trimestral.

Es preciso señalar, que el sistema de financiación pública de medicamentos no pasa por su mejor momento. Son frecuentes las críticas al sistema por falta de transparencia del Gobierno a la hora de fijar los criterios para la financiación pública de medicamentos y la excesiva discrecionalidad en los procedimientos tramitados para ello. Estos motivos ya fueron señalados por la Comisión Nacional de Mercados y la Competencia en mayo de 2015, y recientemente, el Tribunal de Cuentas en su Informe núm. 1.185, de 12 de enero de 2017, sobre Fiscalización de la actividad económica desarrollada por el Ministerio de Sanidad, Servicios Sociales e Igualdad en relación con el área farmacéutica, ejercicios 2014 y 2015 . No obstante, en septiembre de 2015 se publicó el proyecto de Real Decreto por el que se regula la financiación y fijación de precios de medicamentos y productos sanitarios y su inclusión en la prestación farmacéutica del Sistema Nacional de Salud, que se encuentra en estos momentos sometido a fase de consulta pública. Habrá que esperar, si finalmente este proyecto ve la luz, para ver cómo queda regulado el sistema de financiación pública de los medicamentos.

Analizados, pues, los principios generales que rigen la selección de medicamentos, entramos ya en los siguientes apartados en el análisis del procedimiento de subasta establecido en Andalucía y las controversias jurídicas que el mismo plantea.

\section{EL PROCEDIMIENTO DE SUBASTA DE MEDICAMENTOS EN LA LEY DE FARMACIA DE ANDALUCÍA}

El procedimiento de subasta de medicamentos tiene por finalidad seleccionar los medicamentos que deben dispensarse garantizando su dispensación al menor coste. Esta medida surge en un contexto de crisis económica como la propia Junta de Andalucía afirma cuando establece que «la grave crisis financiera y económica sobrevenida y la necesidad de los ajustes presupuestarios correspondientes para la Comunidad Autónoma de Andalucía, hacen imprescindible la adopción de medidas de eficiencia y sostenibilidad económica, que permitan mantener las prestaciones asistenciales actuales y la cobertura universal de la población al tiempo que se hace frente a las obligaciones y compromisos presupuestarios» ${ }^{16}$. Con este procedimiento se pretende alcanzar un doble objetivo: de una parte, disminuir el gasto en medicamentos y productos sanitarios del Sistema Sanitario Público de Andalucía, aprovechando los mecanismos legítimos de competencia

14 Y desarrollado en el Real Decreto 177/2014, de 21 de marzo, por el que se regula el sistema de precios de referencia y de agrupaciones homogéneas de medicamentos en el Sistema Nacional de Salud, y determinados sistemas de información en materias de financiación y precios de medicamentos y productos sanitarios.

15 Los conjuntos incluyen todas las presentaciones de medicamentos financiadas que tengan el mismo principio activo e idéntica vía de administración, entre las que existirá incluida en la prestación farmacéutica del Sistema Nacional de Salud, al menos, una presentación de medicamento genérico o biosimilar, salvo que el medicamento o su ingrediente activo principal hayan sido autorizados con una antelación mínima de diez años en un Estado miembro de la Unión Europea, en cuyo caso no será indispensable la existencia de un medicamento genérico o biosimilar para establecer un conjunto. Las presentaciones indicadas para tratamientos en pediatría, así como las correspondientes a medicamentos de ámbito hospitalario, incluidos los envases clínicos, constituirán conjuntos independientes (art. 98.2).

16 Exposición de motivos del Decreto-Ley 3/2011, de 13 de diciembre, por el que se aprueban medidas urgentes sobre prestación farmacéutica del Sistema Sanitario Público de Andalucía. 
que establece el mercado; y de otra, contribuir a la mejora de la calidad de la dispensación, al disminuir los inconvenientes que supone para los pacientes el cambio de presentación en las sucesivas dispensaciones.

Es importante señalar que quedan fuera del ámbito de aplicación del procedimiento de subasta los medicamentos no prescritos por principio activo. Es cierto que, según el TRLGURM de 2015, sólo se excepcionan de la regla general -prescripción por principio activo- dos supuestos en los que se podrá identificar el medicamento o producto sanitario por su nombre comercial, y no necesariamente por el principio activo. Se trata, por un lado, del caso en que el profesional considere que se dan necesidades terapéuticas que lo justifican; $y$, por otro lado, cuando el medicamento pertenezca a agrupaciones integradas exclusivamente por un medicamento y sus licencias, al mismo precio que el medicamento de referencia. Por tanto, si el medicamento prescrito es de los de menor precio (dentro de los que contengan el mismo principio activo, la misma dosificación y la misma vía de administración), el farmacéutico habrá de dispensar ese y no podrá sustituirlo por otro aunque tenga el mismo precio (salvo en los casos también excepcionales relacionados con el desabastecimiento o la concurrencia de razones de urgente necesidad en la dispensación, previstos en el art. 89 TRLGURM). En estos supuestos, pues, no se aplica el procedimiento de subasta.

El procedimiento de subasta de medicamentos se introduce en la LFA a través del Decreto Ley 3/2011, de 13 de diciembre, por el que aprueban medidas urgentes sobre prestación farmacéutica del sistema sanitario público de Andalucía, que crea un nuevo art. 60 bis en la LFA que tiene por objeto la regulación de este procedimiento. En él se establece que para cada formulación de principio o principios activos, se seleccionará el medicamento del laboratorio farmacéutico cuya propuesta represente para el Servicio Andaluz de Salud el menor coste final de la prescripción correspondiente de entre los propuestos. Para los cálculos oportunos se tendrá en cuenta la diferencia entre el precio autorizado de cada medicamento y la cuantía de la mejora económica ofrecida al Servicio Andaluz de Salud por el laboratorio farmacéutico correspondiente. Además, para garantizar el suministro, se requerirá que los laboratorios farmacéuticos acrediten una capacidad de producción previa suficiente de medicamentos de forma farmacéutica igual al propuesto, así como declaración expresa de asumir el compromiso de garantizar su adecuado abastecimiento.

En consecuencia, sólo se pueden dispensar por las oficinas de farmacia los medicamentos previamente seleccionados por el Servicio Andaluz de Salud. Esta es la principal consecuencia del procedimiento de subasta de medicamentos con respecto a lo que ocurre en el resto del territorio nacional donde los medicamentos se seleccionan no por el servicio de salud autonómico sino por las oficinas de farmacia de entre los recogidos en el Nomenclátor estatal que es la base de datos que recoge los medicamentos sometidos a financiación pública en el SNS y según el sistema de precios de referencias establecido por el Estado.

La puesta en funcionamiento de este sistema en Andalucía, por tanto, ha supuesto un cambio significativo en el sistema de selección de los medicamentos. Hasta el momento las oficinas de farmacia eran las que negociaban con los laboratorios farmacéuticos el precio del medicamento dentro de los márgenes establecidos por el Estado. Ahora es el Servicio Andaluz de Salud el que se beneficia de la negociación al seleccionar el medicamento con el precio más bajo de los ofertados por los laboratorios farmacéuticos.

Hasta la fecha, y desde 2012, se han celebrado diez subastas de medicamentos ${ }^{17}$, y se han firmado los correspondientes convenios con los laboratorios adjudicatarios, tal y como expresa el art. 60 quater de la LFA, que establece que los compromisos entre el Servicio Andaluz de Salud y los laboratorios farmacéuticos o las empresas proveedoras de productos sanitarios, derivados de la selección y sus efectos económicos, quedarán establecidos en los convenios correspondientes, suscritos por la persona titular de la Dirección Gerencia del mismo y por los representantes legales de aquéllos, con sujeción a las normas específicas establecidas en esta ley. Dichos convenios tienen la duración prevista en cada convocatoria de selección, que en todo caso no podrán tener un plazo de vigencia superior a dos años.

\section{CUESTIONES CONTROVERTIDAS DEL PROCEDIMIENTO DE SUBASTA DE MEDICAMENTOS EN ANDALUCÍA}

El sistema de subasta de medicamentos establecido por Andalucía ha sido, como comentábamos en la introducción, muy cuestionado tanto por el gobierno central como por los laboratorios farmacéuticos. El

17 Resoluciones de 25 de enero de 2012; 20 de diciembre de 2012; 20 de junio de 2013; 31 de marzo de $2014 ; 9$ de octubre de 2014; 9 de diciembre de 2014; 15 de mayo de 2015; 29 de abril de 2016; 21 de julio de 2016, y 28 de octubre de 2016, de la Dirección Gerencia del Servicio Andaluz de Salud (SAS) para la selección de medicamentos. 
primero, preocupado por la posible invasión competencial y los segundos, por la vulneración del principio de igualdad de trato que genera el sistema con respecto al resto del territorio nacional.

Es preciso destacar que aunque la subasta de medicamentos ha sido una medida de contención del gasto farmacéutico pionera en nuestro país, también otras Comunidades Autónomas han adoptado con la misma finalidad algunas medidas que afectan a la prestación farmacéutica. Es el caso, por ejemplo, de la Ley 12/2010, de 22 de diciembre, de racionalización del gasto en la prestación farmacéutica de la Comunidad Autónoma de Galicia, que creó un catálogo propio (llamado «priorizado») de medicamentos financiados por la Comunidad Autónoma de Galicia, distinto al catálogo estatal. De conformidad con dicha Ley, el catálogo se formaba por los principios activos, con sus respectivas presentaciones, que respondían al precio menor recogido en el Nomenclátor oficial de productos farmacéuticos financiados por el SNS. De este modo, se obliga al facultativo a la prescripción de los productos incluidos en el catálogo autonómico, más reducido que el nomenclátor estatal en el que se incluyen todos los medicamentos que gozan de financiación pública y, por tanto, se incluyen en la prestación farmacéutica del SNS, reduciendo así el ámbito objetivo de la prestación, puesto que el catálogo incluía menos medicamentos que en el resto del Estado. Esta medida fue también cuestionada por posible vulneración de competencias estatales. Sin embargo, el Tribunal Constitucional en su sentencia 211/2014, de 18 de diciembre, desestimó el recurso de inconstitucionalidad interpuesto por el Gobierno al entender que el catálogo gallego no invadía competencias estatales, ya que el nivel mínimo homogéneo o nivel de suficiencia de prestaciones sanitarias públicas fijado por el Estado puede ser susceptible de mejora, en su caso, por las comunidades autónomas en virtud de su competencia sustantiva y de su autonomía financiera siempre y cuando no contravengan las exigencias que impone el principio de solidaridad.

En lo que a nosotros nos interesa, y al objeto de clarificar las distintas cuestiones jurídicas que afectan a la subasta de medicamentos, podemos identificar las siguientes:

a) Aplicación de la legislación de contratos del sector público al procedimiento de subasta de medicamentos.

b) Infracción de la Ley 20/2013, de 9 de diciembre, de garantía de la unidad de mercado.

c) Vulneración del derecho a la igualdad de los ciudadanos en el acceso a la prestación farmacéutica.

d) Vulneración de las competencias exclusivas del Estado en materia de legislación sobre productos farmacéuticos y bases y coordinación general de la sanidad (art. 149.1.16 CE).

\subsection{Aplicabilidad de la legislación de contratos del sector público al procedimiento de subasta de medicamentos}

La primera de las cuestiones controvertidas que hemos señalado es la sujeción del procedimiento de selección de medicamentos a la Ley de Contratos del Sector Público (en adelante, LCSP) ${ }^{18}$ y, en concreto, a las disposiciones que la misma recoge sobre el contrato de suministro. En efecto, en principio, parece que la forma más adecuada para la adquisición de medicamentos por la Administración sanitaria sería mediante el contrato de suministro regulado en el art. 9 de la $\operatorname{LCSP}^{19}$ y adjudicado a través de los procedimientos pre-

18 Real Decreto Legislativo 3/2011, de 14 de noviembre, por el que se aprueba el Texto Refundido de la Ley de Contratos del Sector Público.

19 Que establece que:

«1. Son contratos de suministro los que tienen por objeto la adquisición, el arrendamiento financiero, o el arrendamiento, con o sin opción de compra, de productos o bienes muebles.

2. Sin perjuicio de lo dispuesto en la letra b) del apartado 3 de este artículo respecto de los contratos que tengan por objeto programas de ordenador, no tendrán la consideración de contrato de suministro los contratos relativos a propiedades incorporales o valores negociables.

3. En todo caso, se considerarán contratos de suministro los siguientes:

a) Aquellos en los que el empresario se obligue a entregar una pluralidad de bienes de forma sucesiva y por precio unitario sin que la cuantía total se defina con exactitud al tiempo de celebrar el contrato, por estar subordinadas las entregas a las necesidades del adquirente. No obstante, la adjudicación de estos contratos se efectuará de acuerdo con las normas previstas en el Capítulo II del Título II del Libro III para los acuerdos marco celebrados con un único empresario.

b) Los que tengan por objeto la adquisición y el arrendamiento de equipos y sistemas de telecomunicaciones o para el tratamiento de la información, sus dispositivos y programas, y la cesión del derecho de uso de estos últimos, a excepción de los contratos de adquisición de programas de ordenador desarrollados a medida, que se considerarán contratos de servicios. 
vistos en dicha Ley, es decir, procedimiento abierto; restringido; procedimiento negociado y diálogo competitivo $^{20}$. Sin embargo, las resoluciones del Servicio Andaluz de Salud convocando la selección de medicamentos excluyen específicamente la aplicación de dicha normativa, al amparo de lo previsto en el art. 4.1.d) de la LCSP, que excluye de su ámbito de aplicación "Los convenios que, con arreglo a las normas específicas que los regulan, celebre la Administración con personas físicas o jurídicas sujetas al derecho privado, siempre que su objeto no esté comprendido en el de los contratos regulados en esta Ley o en normas administrativas especiales». Y además, utiliza un procedimiento de adjudicación por «subasta» que ya no existe en la LCSP, pues, como es sabido, ahora la adjudicación se efectúa en un procedimiento abierto, en el que el criterio objetivo para la adjudicación más valorado puede ser el precio, pero no el único.

Esta cuestión fue objeto de recurso por Farmaindustria (Asociación Nacional Empresarial de la Industria Farmacéutica establecida en España) ante el Tribunal Administrativo de Recursos Contractuales de Andalucía (TARCA), quien en su Resolución de 17 de diciembre de 2012, inadmitió el recurso al entender que la selección de medicamentos no es un contrato regido por el LCSP porque la regulación que de la misma realiza la LFA agota en sí misma el marco normativo del procedimiento de selección y no finaliza con un contrato sino con un convenio, pero sin entrar a enjuiciar si la normativa andaluza vulnera la legislación de contratación pública.

En el mismo sentido, podemos señalar la Resolución 20/2012, del Tribunal Administrativo de Recursos Contractuales de la Junta de Andalucía (TARCA), de 8 de marzo de 2012, sobre el recurso 19/2012. Dicha Resolución trae su origen en un recurso especial en materia de contratación interpuesto contra la Resolución de la Dirección Gerencia del Servicio Andaluz de Salud, de 25 de enero de 2012. En concreto, dicha resolución establece que "A la vista de la regulación legal y enlazando con la consideración previa antes realizada, la especialidad del recurso en materia de contratación, cuyo objeto queda claramente delimitado en el artículo 40 del TRLCSP, no permite que el mismo pueda hacerse extensivo a otro tipo de actos que, como en el supuesto analizado, ni son preparatorios, ni se encuadran en un procedimiento de adjudicación de un contrato sujeto al TRLCSP. En definitiva, la competencia de este Tribunal, a través del recurso especial, no puede extenderse a enjuiciar más que determinados actos producidos en el curso de la licitación de uno de los contratos en los que aquél este previsto, y ello no acontece en el supuesto examinado donde el procedimiento de selección de los medicamentos a que se refiere el artículo 60 bis de la Ley de Farmacia de Andalucía culmina con la suscripción del convenio a que se refiere el artículo 60 quater, como negocio excluido del ámbito de aplicación de la legislación de contratos del sector público».

En cualquier caso, entendemos que resulta necesario un pronunciamiento sobre la verdadera naturaleza, contractual o no, de la figura utilizada por Andalucía, porque la exclusión de la LCSP atendiendo a que se trata de un convenio y no un contrato, genera algún interrogante, pues los convenios excluidos de la aplicación de la LCSP son los celebrados entre la Administración y los particulares siempre que su objeto no esté comprendido en el de los contratos regulados en la Ley, y en el caso que nos ocupa, parece claro que nos encontramos ante un contrato de suministro en el que la Administración sanitaria adquiere un producto, en este caso, de carácter sanitario como son los medicamentos.

\subsection{Infracción de la Ley $20 / 2013$, de 9 de diciembre, de garantía de la unidad de mercado}

Se ha destacado también la posible vulneración de la Ley 20/2013, de 9 de diciembre, de garantía de la unidad de mercado (en adelante, LGUM). Esta Ley regula las disposiciones necesarias para hacer efectivo el principio de unidad de mercado en el territorio nacional, y tiene por objeto, en particular, garantizar la integridad del orden económico y facilitar el aprovechamiento de economías de escala y alcance del mercado mediante el libre acceso, ejercicio y la expansión de las actividades económicas en todo el territorio nacional garantizando su adecuada supervisión, de conformidad con los principios contenidos en el artículo 139 de la CE. Dicha unidad de mercado se fundamenta en la libre circulación y establecimiento de los operadores económicos, en la libre circulación de bienes y servicios por todo el territorio español, sin que ninguna autoridad pueda obstaculizarla directa o indirectamente, y en la igualdad de las condiciones básicas de ejercicio de la actividad económica.

c) Los de fabricación, por los que la cosa o cosas que hayan de ser entregadas por el empresario deban ser elaboradas con arreglo a características peculiares fijadas previamente por la entidad contratante, aun cuando ésta se obligue a aportar, total o parcialmente, los materiales precisos.».

20 Arts. 138 y ss de la LCSP. 
Pues bien, siendo la prestación farmacéutica, como dijimos en el epígrafe segundo de este trabajo al analizar los principios generales, un servicio público de interés general prestado de forma privada, como tal actividad privada de carácter económico está sometida a la libertad de empresa ${ }^{21}$. Por tanto, habría que analizar si el procedimiento de subasta de medicamentos supondría un obstáculo a la unidad de mercado. Sobre ello se planteó en 2014 por una empresa farmacéutica un procedimiento de defensa de la unidad de mercado ante la Secretaría del Consejo para la Unidad de Mercado ${ }^{22}$, quién en su informe de valoración sobre la reclamación, de 5 de mayo de 2014, estableció que la venta de medicamentos (en este caso, como prestación privada de servicios públicos) constituye una actividad económica y como tal está incluida en el ámbito de aplicación de la LGUM y por tanto, cualquier mecanismo de acceso de los operadores económicos al mercado, en este caso, el sistema de convocatorias públicas para la selección de determinado medicamento, debe respetar los principios de la LGUM. Sin embargo, el uso de un sistema de subastas como mecanismo de asignación o provisión no puede considerarse en sí mismo una restricción de acceso a un mercado en la medida en que su diseño garantice el acceso de los operadores y genere competencia por el mercado ex ante y ex post, y siempre que la subasta no contenga requisitos discriminatorios ni prohibidos por la LGUM en su art. 18, ni requisitos innecesarios y/o desproporcionados que limiten la participación de los operadores en la misma ${ }^{23}$. Por tanto, como el procedimiento de subasta de medicamentos es un procedimiento abierto en el que pueden participar, tal y como establece el art. 60 bis LFA, todos los laboratorios farmacéuticos interesados o todas las empresas proveedoras de productos sanitarios, parece que no existe ninguna restricción ni condición adicional para el acceso al mercado, y por ende, no existe vulneración de la LGUM.

\subsection{Vulneración de las competencias exclusivas del Estado para garantizar la igualdad de todos los ciudadanos (149.1.1 CE) y en materia de bases y coordinación general de la sanidad y legislación sobre productos farmacéuticos (art. 149.1.16 CE)}

Las cuestiones conflictivas más complejas que se han planteado en el procedimiento de subasta de medicamentos andaluz han sido la posible vulneración de las competencias exclusivas del Estado recogidas en el 149.1.1 CE (regulación de las condiciones básicas que garanticen la igualdad de todos los españoles en el ejercicio de los derechos y el cumplimiento de los deberes constitucionales) y en el 149.1.16. ${ }^{\mathrm{a}}$ CE (bases y coordinación general de la sanidad y legislación sobre productos farmacéuticos).

Estas cuestiones se han planteado ante el TC a través de dos procedimientos diferentes. En primer lugar, con un conflicto positivo de competencias planteado por el Gobierno central contra la resolución de la primera convocatoria del concurso para la selección de medicamentos de 25 de enero de $2012^{24}$, y en segundo término, con un recurso de inconstitucionalidad contra el artículo único del Decreto-ley Andaluz $3 / 2011$, de 13 de diciembre, por el que se aprueban medidas urgentes sobre la prestación farmacéutica del sistema sanitario público de Andalucía, por el que se introduce en la LFA el art. 60 bis que regula el procedimiento de subasta de medicamentos ${ }^{25}$. En ambos procedimientos se argumenta por el Gobierno central que

21 Tal y como analizamos en "La ordenación farmacéutica en Andalucía” en PÉREZ MONGUIO, J. M. y FERNÁNDEZ RAMOS, S. (dir.), El Derecho de Salud Pública y Políticas Sociales e lgualdad en Andalucía, Ed. IAAP, 2016, págs. 197 a 201.

${ }^{22}$ Es el órgano técnico de coordinación y cooperación continua con las autoridades competentes para la aplicación de esta Ley y tiene las siguientes funciones recogidas en el art. 11 LGUM:

a) Supervisión continúa de la aplicación de esta Ley y de la adaptación de la normativa del conjunto de las autoridades competentes.

b) Análisis y evaluación de la situación de la unidad de mercado en el territorio nacional.

c) Elaboración de un catálogo de buenas y malas prácticas que tienen efectos sobre la unidad de mercado, que será aprobado por el Consejo para la Unidad de Mercado.

d) Elaboración y difusión de indicadores de calidad normativa respecto a la unidad de mercado y su impacto económico.

e) Gestión de los mecanismos de protección de los operadores económicos en el ámbito de la unidad de mercado en el marco de lo previsto en el Capítulo VII de la Ley.

f) Elaboración de un informe de carácter semestral sobre las letras anteriores con conclusiones y, en su caso, recomendaciones para la revisión o reforma de marcos jurídicos.

g) Articulación de acciones de cooperación y actividades conjuntas entre autoridades competentes.

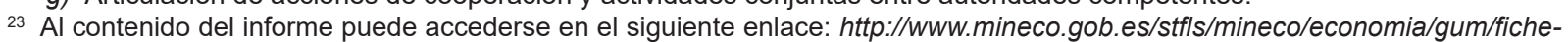
ros/SANIDADMedicamentos.pdf.

${ }_{24}$ Conflicto positivo de competencias núm. 1.923/2012, admitido a trámite por providencia del Tribunal Constitucional de 12 de marzo de 2013.

${ }_{25}$ Recurso de inconstitucionalidad 4.539/2012, admitido a trámite por providencia del Tribunal Constitucional de 24 de julio de 2012. 
la regulación de la prescripción de medicamentos por Andalucía vulnera la competencia exclusiva estatal en materia de legislación sobre productos farmacéuticos (art. 149.1.16 CE); que la subasta de medicamentos modifica la cartera básica de servicios, aprobada por el Estado, mediante el Decreto 1.030/2006, en el ejercicio de su competencia para establecer las bases y la coordinación general de la sanidad (art. 149.1.16 CE), al excluir determinados medicamentos del ámbito de dichas prestaciones básicas, que son susceptibles de ampliación, pero no de restricción por las Comunidades Autónomas; y que las competencias estatales se vulneran al establecer Andalucía un régimen que viene a modificar la cobertura de la prestación de financiación de medicamentos en el Sistema Nacional de Salud, implantando un régimen de financiación que resulta discriminatorio.

Sin embargo, las sentencias dictadas por el Alto Tribunal en estos procedimientos (SSTC 210/2016, de 15 de diciembre y $7 / 2017$, de 19 de enero) han entendido que el procedimiento de subasta de medicamentos instaurado en Andalucía no es inconstitucional y, por tanto, no vulnera ninguna competencia exclusiva del Estado ${ }^{26}$

Con respecto a la posible vulneración del derecho a la igualdad de los ciudadanos en el acceso a la prestación farmacéutica, debemos recordar, en primer lugar, que el art. 88.1 de la Ley 29/2006, de 26 de julio, de garantías y uso racional de los medicamentos y productos sanitarios ${ }^{27}$, vigente en ese momento, reconocía el derecho de todos los ciudadanos a obtener medicamentos en condiciones de igualdad en todo el SNS, sin perjuicio de las medidas tendentes a racionalizar la prescripción y la utilización de medicamentos y productos sanitarios que puedan adoptar las Comunidades Autónomas en ejercicio de sus competencias. Por tanto, tales medidas no pueden producir diferencias en las condiciones de acceso a los medicamentos y productos sanitarios financiados por el SNS, catálogo y precios, debiendo ser homogéneas para la totalidad del territorio español y sin producir distorsiones en el mercado único de medicamentos y productos sanitarios.

Pareciera que dichas condiciones de igualdad podrían verse alteradas en Andalucía con la subasta de medicamentos, pues los andaluces sólo pueden acceder a los medicamentos previamente seleccionados, lo que, en definitiva, supondría un acceso a la prestación farmacéutica más restringida que los residentes en otras comunidades autónomas. En este sentido, es preciso recordar que el TC ha declarado que los criterios de igualdad y equidad, en el ámbito de las prestaciones sanitarias, obligan al Estado a garantizar un mínimo común denominador, es decir, un nivel mínimo que debe ser compatible con el desarrollo de situaciones diferenciales en su contenido, formas o requisitos de aplicación ${ }^{28}$. Ello significa que la regulación básica establecida por el Estado, no habilita para exigir o imponer a las comunidades autónomas una uniformidad

${ }_{26}$ Ya parecían premonitorios los argumentos del TC recogidos en los autos 147/2012, de 16 de julio y $238 / 2012$, de 12 de diciembre, dictados para levantar la suspensión cautelar adoptada sobre la normativa andaluza tras la admisión a trámite de ambos procedimientos, pues si bien, como dice el Tribunal en su resolución ello no vincula a lo en su día se adopte respecto del debate de fondo, son de utilidad para una mayor comprensión del problema planteado. En este sentido, entiende el Tribunal que «la sostenibilidad del sistema sanitario público impone a todos los poderes públicos la necesidad de adoptar medidas de racionalización y contención del gasto farmacéutico pues es uno de los principales componentes del gasto sanitario y en el que más pueden incidir las políticas de control del mismo, tanto más necesarias en una situación como la actual caracterizada por una exigente reducción del gasto público. La contención y reducción del gasto farmacéutico es, por tanto, un objetivo a conseguir por la totalidad de las estructuras del Sistema Nacional de Salud». De este modo, dice el Tribunal «las Administraciones públicas con competencias en la materia tienen la obligación de distribuir equitativamente los recursos públicos disponibles a fin de garantizar la sostenibilidad del sistema público de salud favoreciendo el uso racional de los medicamentos e instaurando políticas de contención del gasto». Por ello, "resulta congruente con tal objetivo que sea la Administración sanitaria, y no los particulares, quien resulte directamente beneficiaria de la minoración del precio de los medicamentos». Afirma también que es claro que «el modelo estatal, con su preferencia por la prescripción por principio activo y la introducción del precio como criterio en la dispensación y sustitución de medicamentos, implica que va a ser siempre dispensada la presentación comercial de precio menor, con independencia de que sea la misma que hubiera venido tomando el paciente con anterioridad, sin que tampoco garantice el derecho a la dispensación de una determinada presentación comercial de un medicamento, pues es claro que la prestación farmacéutica del sistema nacional de salud no se configura en tales términos. Por el contrario, siendo el criterio general la prescripción por principio activo y la dispensación atendiendo al menor coste posible, no se alcanza a comprender, desde la perspectiva cautelar que ahora hemos de adoptar, que la concreción centralizada en toda la Comunidad Autónoma de la dispensación de determinados medicamentos señalados por su principio activo y atendiendo a criterios de coste del medicamento concreto a dispensar, suponga un perjuicio irreparable respecto al que deriva de un sistema en el que esa determinación corresponde al titular de la oficina de farmacia, pues ha de atenderse a consideraciones de precio del medicamento, ya que, en todo caso, ha de dispensarse el de menor precio y, en caso de igualdad del precio, el genérico».

27 Y en el mismo sentido se recoge en el art. 91 del Real Decreto Legislativo 1/2015, de 24 de julio, por el que se aprueba el Texto Refundido de la Ley de garantías y uso racional de los medicamentos y productos sanitarios, que ha venido a derogar a la Ley $29 / 2006$, de 26 de julio.

28 SSTC 37/1987, de 26 de marzo, 14/1998, de 22 de enero y 54/1990, entre otras. 
REALA. Nueva Época - N. 7, mayo 2017 - ISSN: 1989-8975 - DOI: 10.24965/reala.v0i7.10422 - [Págs. 126-142]

La subasta de medicamentos en Andalucía. Cuestiones controvertidas y perspectivas de futuro

Elsa Marina Álvarez González

total y absoluta en el nivel de las prestaciones sanitarias, pero sí que todas las comunidades autónomas contando con más recursos puedan llegar a que todos los ciudadanos tengan garantizada la igualdad en el servicio público sanitario, y concretamente, el farmacéutico.

Sobre esta cuestión, el TC ha establecido, en su sentencia 136/2012, que la decisión acerca de quienes deban ser beneficiarios de las prestaciones sanitarias y cuáles sean dichas prestaciones, pertenece indudablemente al núcleo de lo básico, pues define los ámbitos subjetivo y objetivo de la propia materia. En efecto, la definición de quienes pueden considerarse asegurados y en consecuencia tener acceso al SNS, así como las concretas prestaciones sanitarias que deben ser garantizadas a todos ellos, por integrarse en la cartera común, permite establecer un común denominador normativo dirigido a asegurar, de manera unitaria y en condiciones de igualdad, el acceso a la sanidad por parte de todos los ciudadanos incluidos en el ámbito subjetivo de la norma, con independencia de su lugar de residencia. En consecuencia, forma lógicamente también parte del ámbito de lo básico la concreta definición de las diferentes modalidades de prestaciones sanitarias comunes (básicas, suplementarias o de servicios accesorios). Además, también por aplicación de la jurisprudencia constitucional (SSTC 98/2004, de 25 de mayo y 22/2012, de 16 de febrero) cabe considerar como básica la definición del sistema de financiación de la sanidad, lo que incluye tanto la garantía general de financiación pública como, dentro de esta garantía, los supuestos en los que algunas prestaciones comunes que no son básicas (las suplementarias y de servicios accesorios) pueden estar sujetas a una financiación adicional con cargo al usuario del servicio (tasa o copago). En efecto, sostiene el Tribunal que «la definición de la modalidad de financiación aplicable a las diferentes prestaciones sanitarias, y en qué supuestos procede el pago de aportaciones por sus destinatarios, tiene una incidencia central en la forma de prestación del propio servicio, constituyendo así también un elemento nuclear del propio ámbito objetivo de las prestaciones sanitarias, que en consecuencia debe ser regulado de manera uniforme, por garantizar el mínimo común de prestaciones sanitarias cubierto por financiación pública en todo el territorio nacional». Dichas bases habilitan un margen para el desarrollo por parte de las comunidades autónomas de su propia política sanitaria. Éstas podrán, respetando el mínimo formado por las carteras comunes, aprobar sus propias carteras de servicios y establecer servicios adicionales para sus residentes.

En cualquier caso, en el asunto que nos ocupa, el TC no ha entrado a enjuiciar la vulneración del art. 149.1.1 CE al entender que «dada la función uniformadora que ha de cumplir la normativa básica, ha de señalarse que tal competencia [del art. 149.1.1 CE] queda absorbida por la que le corresponde al Estado en la regulación de las bases de la sanidad, que es más específica y puede dotarse también de un mayor contenido» (STC 109/2003, de 5 de junio, FJ 3). A ello hay que unir que el TC descarta también el título competencial relativo a la «legislación sobre productos farmacéuticos» (de competencia exclusiva del Estado conforme al 149.1.16 CE), por entender que no forman parte los preceptos impugnados «de ese conjunto de normas que tiene por objeto la ordenación de los medicamentos en cuanto 'sustancias' cuya fabricación y comercialización está sometida -a través de las correspondientes actividades de evaluación, registro, autorización, inspección y vigilancia- al control de los poderes públicos, en orden a garantizar los derechos de los pacientes y usuarios que los consumen» (STC 98/2004, de 25 de mayo, FJ 5), puesto que, la norma andaluza al abordar la regulación de la selección de los medicamentos o productos sanitarios a dispensar por las oficinas de farmacia cuando se indiquen por principio activo o denominación genérica está regulando el medicamento en su dimensión de «prestación sanitaria» del sistema de salud. Por tanto, todo el análisis de la STC 210/2016, de 15 de diciembre, se centra en el análisis del título competencial de bases de la sanidad recogido en el art. 149.1.16. ${ }^{a} \mathrm{CE}$.

Además, no debemos perder de vista que la norma impugnada ha de someterse al contraste con los arts. 87 y 91 del TRLGURM de 2015 -antiguos arts. 85 y 88 de la Ley 29/2006, de 26 de julio-, pues dichos preceptos han experimentado diversas modificaciones desde que se interpuso el recurso de inconstitucionalidad, y el análisis que hace el TC parte de la redacción vigente en el momento de dictar sentencia, pues aplica la doctrina de la inconstitucionalidad mediata (SSTC 161/2014, de 7 de octubre, y 171/2014, de 23 de octubre). Los efectos que de ello deriva son muy relevantes pues la Ley 29/2006, de 26 de julio, vigente en aquel momento, establecía en su art. 85.4 que cuando la prescripción se realice por principio activo, el farmacéutico dispensará el medicamento de precio más bajo de su agrupación homogénea y, en el caso de igualdad, el medicamento genérico o el medicamento biosimilar correspondiente. Sin embargo, con el sistema de subastas andaluz, que se hace atendiendo al menor coste, la dispensación de medicamentos por principio activo obligatoriamente se realiza entre los seleccionados en los concursos pudiendo no ser éstos medicamentos genéricos o biosimilares, lo que parece que podría vulnerar la normativa básica estatal en la materia vigente en aquel momento. Pero ahora, esa posible vulneración parece no ser tal, ya que el art. 87 del TRLGURM no exige en caso de igualdad escoger el medicamento genérico. 
Pues bien, entrando en el análisis del título competencial de bases de la sanidad, debemos señalar que la selección de medicamentos y productos sanitarios por el Servicio Andaluz de Salud mediante un sistema de convocatoria pública afecta a la dispensación de productos farmacéuticos. Así, cuando un medicamento se prescriba por principio activo y un producto sanitario se prescriba por denominación genérica, las oficinas de farmacia deberán dispensar el medicamento o producto sanitario seleccionado por el Servicio Andaluz de Salud tras la correspondiente convocatoria pública. En consecuencia, parece claro que la dispensación de prestaciones farmacéuticas constituye un criterio básico en materia de sanidad ${ }^{29}$.

Con ello, se garantiza una uniformidad mínima en las condiciones de acceso a los medicamentos con independencia del lugar en el que se resida del territorio nacional y se evita la introducción de factores de desigualdad en la protección básica de la salud. Sin embargo, esa necesaria uniformidad mínima, que corresponde establecer al Estado, asegurando así un nivel mínimo homogéneo o nivel de suficiencia de las prestaciones sanitarias públicas, puede ser susceptible de mejora, en su caso, por parte de las comunidades autónomas, en virtud de su competencia sustantiva y de su autonomía financiera, siempre y cuando, con ello, no se contravengan las exigencias que impone el principio de solidaridad (arts. 2 y $138 \mathrm{CE})^{30}$. Efectivamente, la Constitución Española no sólo atribuye al Estado una facultad, sino que le exige que preserve la existencia de un sistema normativo sanitario nacional con una regulación uniforme mínima y de vigencia en todo el territorio español, eso sí, sin perjuicio, bien de las normas que sobre la materia puedan dictar las comunidades autónomas en virtud de sus respectivas competencias dirigidas, en su caso, a una mejora en su ámbito territorial de ese mínimo común denominador establecido por el Estado, bien de las propias competencias de gestión o de financiación que sobre la materia tengan conforme a la Constitución y a los Estatutos.

Esto se concreta en el art. 23 de la Ley 16/2003, de 28 de mayo, de Cohesión y Calidad del Sistema Nacional de Salud, que establece que todos los usuarios del SNS tendrán acceso a las prestaciones sanitarias en ella reconocidas en condiciones de igualdad efectiva. $Y$ siendo una de las citadas prestaciones el medicamento, es evidente que el acceso al mismo en condiciones de igualdad presupone necesariamente una regulación uniforme mínima y de vigencia en todo el territorio español.

Para el TC, el derecho de todos los ciudadanos a obtener medicamentos en condiciones de igualdad en todo el SNS, se reconoce sin perjuicio de las medidas tendentes a racionalizar la prescripción y la utilización de medicamentos y productos sanitarios que puedan adoptar las comunidades autónomas en ejercicio de sus competencias (art. 91.1 TRLGURM), de tal modo que, no estando discutidas las competencias de la Comunidad Autónoma de Andalucía en materia de sanidad, dice el TC que «la cuestión se reduce a valorar si en su ejercicio ha desbordado los límites que impone el citado precepto de la Ley estatal (STC 211/2014, de 18 de diciembre, FJ 6), que, en cuanto aquí importa, se concretan en que la selección de un único medicamento para cada formulación de principio activo y de un único producto sanitario para cada grupo o tipo de producto sanitario o conjunto de intercambio no produzca diferencias en las condiciones de acceso a los medicamentos y productos sanitarios financiados por el Sistema Nacional de Salud, catálogo de prestaciones y precio».

En la Comunidad Autónoma de Andalucía de entre los medicamentos comercializados que tengan un precio autorizado igual o inferior al precio menor correspondiente establecido en el SNS, el Servicio Andaluz de Salud selecciona, mediante la correspondiente convocatoria pública, aquél que deberá ser dispensado por el farmacéutico cuando se le presente una receta médica u orden de dispensación, sin que en ningún caso las mejoras económicas que los laboratorios farmacéuticos ofrezcan al Servicio Andaluz de Salud afecten a los precios de los medicamentos seleccionados. Así, la oficina de farmacia sólo podrá dispensar el medicamento perteneciente al laboratorio farmacéutico que ha sido seleccionado en primer lugar y con el que el Servicio Andaluz de Salud habrá suscrito el correspondiente convenio. Es decir, en Andalucía respecto de los medicamentos sometidos a convocatoria pública, la selección de los medicamentos a dispensar cuando

\footnotetext{
${ }^{29}$ Así lo ha mantenido el TC en la STC 211/2014, de 18 de diciembre. En efecto, la prescripción y dispensación de medicamentos constituye un criterio básico en materia de sanidad, en primer lugar, "porque se satisfacen las exigencias formales de la legislación básica por la inclusión de esta materia en una norma de rango legal, la Ley 29/2006, de 26 de julio. Y, en segundo lugar, porque se satisfacen las exigencias materiales de la legislación básica, pues la prescripción y dispensación de medicamentos es, ciertamente, un aspecto esencial o nuclear de la regulación de la prestación farmacéutica, al ser un presupuesto necesario para el acceso de los ciudadanos a los medicamentos en condiciones de igualdad. Partiendo del carácter básico de la materia en cuestión dentro del marco normativo que regula la sanidad, forzosamente se ha de afirmar que es al Estado al que corresponde su regulación, en tanto que el art. 149.1.16 CE le otorga la competencia exclusiva sobre las bases y coordinación general de la sanidad» (STC 211/2014, de 18 de diciembre, FJ 5).

30 STC 98/2004, de 25 de mayo, FJ 7.
} 
se prescriban por principio activo no la hace la oficina de farmacia, sino que la selección la hace el Servicio Andaluz de Salud. En el sistema estatal, por el contrario, es el farmacéutico el que hace la selección, debiendo dispensar, en caso de que existan varios, el medicamento de precio más bajo de su agrupación homogénea. De este modo, el destinatario de la prestación farmacéutica va a recibir en todo caso el medicamento de precio más bajo, tal y como prevé la norma estatal, la única diferencia es que en Andalucía la selección del precio más bajo la hace el Servicio Andaluz de Salud y en el resto del Estado la hace el farmacéutico, sin que ello suponga perjuicio alguno para el destinatario.

Por otro lado, es cierto que en Andalucía quedan fuera de la cartera de servicios comunes de la prestación farmacéutica aprobada por el SNS, las restantes presentaciones y productos que figuran en el nomenclátor estatal y que, sin embargo, no resulten seleccionadas a través del correspondiente concurso. Pero a este respecto, el TC señala que, por un lado, la inclusión de un medicamento en ese nomenclátor es condición necesaria pero insuficiente para su financiación en cada caso concreto, pues a ello ha de añadirse que para su dispensación es preciso que se trate del medicamento de menor precio dentro de los incluidos en la correspondiente agrupación homogénea, y, por otro que, en la actualidad, tal y como establece el art. 99 TRLGURM, la normativa estatal también excluye de la financiación por el Sistema Nacional de Salud a los medicamentos y/o productos sanitarios que superen el precio máximo financiable seleccionado a pesar de figurar en el nomenclátor.

En consecuencia, determina el TC que la selección por el Servicio Andaluz de Salud, a través de la correspondiente convocatoria pública, de los medicamentos a dispensar por las oficinas de farmacia no establece diferencias en las condiciones de acceso a los medicamentos financiados por el SNS, catálogo y precios. Queda claro, pues, que no hay vulneración ni de las condiciones de igualdad de los ciudadanos en el acceso a la prestación farmacéutica ni de las bases establecidas por el Estado en materia de bases de la sanidad.

\subsection{Un apunte de futuro sobre las subastas de medicamentos}

El procedimiento de subasta de medicamentos establecido en Andalucía, no sólo ha obtenido el respaldo jurídico, como hemos visto, con las recientes sentencias del TC, sino que además, parece que como medida de contención del gasto farmacéutico ha sido efectiva, pues según el Consejero de Salud, el ahorro acumulado desde la primera subasta de medicamentos ha sido de 425,8 millones de euros hasta enero $2017^{31}$. No es de extrañar, por tanto, que ya se hayan manifestado algunas Comunidades Autónomas interesadas en copiar el modelo. Así, por ejemplo, El Consejo de Gobierno de Asturias acaba de anunciar que prevé modificar en este año 2017 su Ley 1/2007, de 16 de marzo, de Atención y Ordenación Farmacéutica, para introducir la subasta de medicamentos ${ }^{32}$. En el mismo sentido, Castilla La Mancha, Extremadura y Valencia que anunciaron a finales de 2016 que estudiarían la implantación de la medida en sus respectivas Comunidades $^{33}$.

Sin embargo, las subastas de medicamentos también presentan algunas deficiencias que están siendo puestas de manifiesto por distintos agentes sociales. Los principales problemas están relacionados con el preocupante desabastecimiento de medicamentos seleccionados que sufren la farmacias andaluzas; el elevado porcentaje de subastas de medicamentos que se quedan desiertas; el auge de los laboratorios extranjeros que han desplazado a los laboratorios farmacéuticos nacionales en la fabricación de medicamentos en Andalucía; la calidad de los medicamentos que se dispensan; y el ahorro económico que parece no ser tan positivo como proclama la Consejería de Salud de la Junta de Andalucía.

En lo que respecta al desabastecimiento de medicamentos, las últimas noticias publicadas señalan que de las 518 agrupaciones homogéneas en las que el Servicio Andaluz de Salud ha seleccionado alguna presentación para su dispensación en farmacias, en 158 se han presentado problemas de abastecimiento,

31 Datos aportados en su intervención en la Comisión de Salud parlamentaria celebrada el 9 de marzo de 2017 (http://www. juntadeandalucia.es/salud/sites/csalud/contenidos/Noticias/2017/03/dia09/Noticia32944?perfil=ciud\&desplegar=\&idioma=es\&tema=/ temas_es/\&contenido=/sites/csalud/contenidos/Noticias/2017/03/dia09/Noticia32944).

${ }_{32}$ Pueden verse las siguientes noticias al respecto: $h t t p s: / / w w w$.diariofarma.com/2017/03/08/subastas-asturias-la-modificacionla-ley-ordenacion-sera-2017; https://www. diariofarma.com/2017/03/09/subastas-asturias-aefas-espera-ver-del-busto-los-grupos-politicos; https://www.diariofarma.com/2017/03/02/asturias-ya-esta-trabajando-implantar-subastas-medicamentos.

${ }_{33}$ Véase: http://www.castillalamancha.es/actualidad/notasdeprensa/el-presidente-garc\%C3\%ADa-page-propone-un-sistema-desubasta-de-medicamentos-similar-al-de-andaluc\%C3\%ADa; $h$ ttp://www.elglobal.net/hemeroteca/las-subastas-podrian-traspasar-la-frontera-andaluza-tras-el-vuelco-electoral-del-24-m-HQEG_913958. 
lo que supone un porcentaje de un 30,5\%, según los datos de la Confederación Empresarial de Oficinas de Farmacia de Andalucía (CEOFA) ${ }^{34}$. Según los datos que maneja la Asociación de Farmacéuticos de Andalucía (AFARAN), el $46 \%$ de los medicamentos seleccionados por el sistema de subasta tienen problemas habituales de abastecimiento ${ }^{35}$. El desabastecimiento parece, pues, que es habitual entre el listado de medicamentos cuya fabricación ha adjudicado la Junta de Andalucía en exclusivas a los laboratorios en virtud de las subastas. Laboratorios farmacéuticos que, por lo general, son empresas radicadas en Europa del este o Asia que han ofrecido precios muy bajos pero que parecen no tener suficiente capacidad de producción para atender toda la demanda de la Comunidad Autónoma. Y ello, a pesar de que el art. 60 bis de la LFA obliga a las empresas adjudicatarias a acreditar tanto una capacidad de producción previa suficiente de medicamentos, así como a declarar expresamente que asumen el compromiso de garantizar su adecuado abastecimiento.

La inactividad de la Administración sanitaria andaluza ante esta situación hizo que AFARAN planteara una queja ante el Defensor del Pueblo Andaluz en julio de 2016. En este procedimiento la Junta de Andalucía negó que existan desabastecimientos que hagan peligrar los tratamientos de los pacientes, ya que la normativa (tanto nacional andaluza), establece los mecanismos necesarios para solventar situaciones puntuales que pudieran producirse ante la falta momentánea de una presentación específica. En efecto, en caso de desabastecimiento se prevé la dispensación de otro preparado comercial con idénticas características dispensado por otra compañía diferente y con una penalización a los laboratorios adjudicatarios. Esta penalización consiste en seguir cobrando de las compañías adjudicatarias de las subastas las cuantías de mejora ofertadas, como si se hubiesen dispensado los medicamentos seleccionados. Por tanto, aunque una compañía adjudicataria no sirva una determinada presentación, el Servicio Andaluz de Salud cobra lo que tenía previsto ya que el laboratorio paga la misma cuantía de mejora por cada unidad dispensada de la agrupación homogénea que le correspondiera, independientemente de que el medicamento dispensado sea el suyo o el de otra compañía de genéricos diferente, a causa del desabastecimiento. Así, mientras los laboratorios adjudicatarios asuman ese pago como penalización, no existe causa para la resolución del contrato y mantienen la exclusividad cuando tengan producto disponible.

Otra de las deficiencias es el elevado porcentaje de presentaciones de medicamentos que quedan desiertas en las subastas. Desde que se inició el sistema de subastas en 2012, y en las seis primeras subastas que se celebran entre 2012 y 2014 sólo se adjudicó el $8 \%$ de las presentaciones convocadas ${ }^{36}$. En las cuatro subastas restantes (celebradas de 2015 a 2016) los resultados son algo mejores. Así, en la séptima se cubre el $29,8 \%{ }^{37}$ y en la octava el $27,45 \%{ }^{38}$ de las licitaciones convocadas; en la novena se ha adjudicado el $16 \%{ }^{39}$ y en la décima el $34 \%$ de los lotes de principios activos que se han sacado a concurso ${ }^{40}$. En cada subasta se convocan las presentaciones que han quedado desiertas en subastas anteriores y los medicamentos que han quedado liberados de la exclusividad al haberse extinguido los contratos. En cualquier caso, parece que el que las grandes compañías farmacéuticas no se presenten a estos procedimientos de subasta por no resultarles rentable los bajos precios de las subastas sería la causa del elevado porcentaje de subastas desiertas. Además, esta situación tiene otro efecto negativo pues el ahorro económico no está siendo el

${ }^{34}$ Véase: https://www.diariofarma.com/2017/03/11/desabastecimiento-las-subastas-alcanza-305-158-presentaciones.

Según CEOFA, los laboratorios adjudicatarios están obligados a acreditar tanto su capacidad de producción como de abastecimiento. Sin embargo, la falta de suministro adecuado se ha producido desde la primera subasta y se intensifica con la entrada de cada nueva convocatoria. Así, en abril de 2013, casi la mitad de los fármacos de las subastas carecían de un abastecimiento adecuado; un año más tarde, 55 moléculas no se suministraban, 28 de las cuales correspondían a un solo laboratorio. A finales de octubre de 2014 sólo estaba disponible el $38 \%$ de los medicamentos solicitados por los almacenes, existiendo cinco laboratorios (de los 12 adjudicatarios) que no servían ninguno. En enero de 2015, había 121 especialidades que tenían un suministro inferior al 50\% del demandado, y uno de cada cinco referencias de las subastas abastecían menos del $30 \%$ de lo requerido por los almacenes de distribución farmacéutica y casi el $10 \%$ de las moléculas subastadas simplemente no se suministraban. En febrero los datos eran bastante similares, existiendo 42 medicamentos de las subastas sin suministrar ni un solo envase ( $h$ ttp://www.actasanitaria.com/aclaraciones-de-ceofasobre-el-desabastecimiento-de-medicamentos-en-las-subastas-andaluzas/).

${ }_{35}$ Véase: http://www.libertaddigital.com/espana/2017-01-09/el-desmadre-de-la-junta-de-andalucia-en-la-compra-y-subasta-de-medicamentos-1276590193/.

${ }^{36}$ Así se recoge en el Informe de 2015 de la consultora Antares Consulting. Véase: https://www.diariofarma.com/2015/05/16/ antares-cifra-el-ahorro-de-las-subastas-andaluzas-en-solo-el-28-del-previsto.

${ }^{37}$ https://www.diariofarma.com/2015/07/16/andalucia-adjudica-a-16-laboratorios-168-presentaciones-en-las-septimas-subastas.

$38 \mathrm{https}$ ://www.redaccionmedica.com/secciones/farmacia/andalucia-solo-cubre-el-27-45-de-los-farmacos-de-la-octavasubasta-686.

39 https://www.diariofarma.com/2016/10/01/sas-adjudica-solo-16-los-lotes-la-novena-subasta-andaluza.

40 https://www.diariofarma.com/2016/12/15/sas-adjudica-solo-34-decimas-subastas-22-laboratorios. 
esperado. En efecto, el gasto farmacéutico en Andalucía ascendía a 2.500 millones de euros por año antes de la entrada en vigor del sistema de subastas, y el objetivo de esta medida era reducir dicho gasto en un $50 \%$, llegando a un ahorro de 200 millones de euros por año. Sin embargo, el ahorro obtenido de las seis primeras adjudicaciones ha alcanzado únicamente el $28 \%$, es decir, 219 millones de euros ${ }^{41}$. Y en las cuatro adjudicaciones restante el ahorro económico asciende a 209 millones de euros. Por tanto, se observa un ahorro total en las diez subastas realizadas muy por debajo de la previsión de partida.

A todo lo anterior debemos unir el hecho de que las principales compañías farmacéuticas que concurren a los procedimientos de subasta son empresas extranjeras. Es decir, están obteniendo la exclusividad en la producción de los medicamentos andaluces, principalmente, laboratorios indios, alemanes, eslovenos y suecos. Desde la primera subasta, celebrada en enero de 2012, los laboratorios que más concesiones han adquirido son el sueco Bluefish Pharma, la alemana Aristo Pharma y los laboratorios de origen indio Aurobindo S. L. y Ranbaxy ${ }^{42}$. Este origen de los fármacos no ofrece seguridad a los pacientes andaluces, colegios de farmacéuticos y otros agentes sanitarios, que señalan una merma en la calidad y efectividad de los medicamentos, tal y como ha señalado la Defensora del Pueblo Andaluz ${ }^{43}$. Además, sería conveniente analizar las consecuencias económicas y productivas que para el sector farmacéutico nacional tiene esta expansión de los laboratorios extranjeros en la producción de los medicamentos andaluces, pues existen ya algunos ejemplos de deslocalización en la producción de fármacos en otros países en los que también existe esta medida, como por ejemplo, en Nueva Zelanda y Alemania ${ }^{44}$.

En consecuencia, creemos que todas estas cuestiones deben ser objeto de una profunda reflexión y análisis antes de iniciar un proceso de adaptación del modelo de subasta de medicamentos en otras Comunidades Autónomas, pues sólo así se evitarán que estos problemas se trasladen y se repitan también en otras regiones.

No obstante, y ante la posible expansión del modelo de subasta de medicamentos es preciso destacar la regulación por el Estado del sistema de precios seleccionados de los medicamentos introducido por el Real Decreto-ley 16/2012, de 20 de abril, de medidas urgentes para garantizar la sostenibilidad del Sistema Nacional de Salud y mejorar la calidad y seguridad de sus prestaciones, y actualmente previsto en el art. 99 TRLGURM de 2015. Este sistema permite establecer el precio máximo seleccionado para los medicamentos y productos sanitarios financiables por el SNS y sujetos a precios de referencia, teniendo en cuenta a) El consumo del conjunto; b) El impacto presupuestario; c) La existencia de, al menos, tres medicamentos en el conjunto; y d) Que no se produzca riesgo de desabastecimiento. Valorados estos criterios, el Ministerio de Sanidad comunica a los proveedores el inicio de un procedimiento de precio seleccionado, con comunicación del precio máximo de financiación que se propone para que manifiesten sus intenciones. En base a las comunicaciones recibidas, el Ministerio elaborará su propuesta que debe ser autorizada por la Comisión Interministerial de Precios de los Medicamentos, teniendo en cuenta que aquellos medicamentos y/o productos sanitarios que superen el precio máximo financiable quedarán excluidos de la financiación por el SNS. El precio seleccionado tendrá una vigencia de dos años durante los cuales no podrá ser modificado. Este sistema se actualizará, para los casos en los que no haya sido aplicado con anterioridad, con periodicidad anual, de forma simultánea a la actualización del sistema de precios de referencia.

La aplicación de este sistema supone la exclusión de la financiación pública de aquellas presentaciones que no resulten seleccionadas, por el tiempo de vigencia del precio seleccionado. Los laboratorios titulares

\footnotetext{
${ }^{41}$ Así se recoge en el Informe de 2015 de la consultora Antares Consulting. Véase: https://www.diariofarma.com/2015/05/16/ antares-cifra-el-ahorro-de-las-subastas-andaluzas-en-solo-el-28-del-previsto.

42 La prensa señala que el laboratorio indio Ranbaxy indio fue multado por la FDA-Agencia de Alimentos y Medicamentos de EE UU- por la vulneración de la ley de seguridad de los medicamentos y por no cumplir las normas de calidad de los medicamentos, por lo que se prohibió la comercialización de cualquier producto proveniente de este laboratorio. No obstante, en Europea se verifica que los compuestos procedentes de la India cumplen con los estrictos controles de calidad de la Agencia Europea del Medicamento, ya que el país asiático es fabricante de parte de muchos de los medicamentos que se comercializan en Europa. Véase, en este sentido: http://www.larazon.es/atusalud/medicamentos-genericos-del-tercer-mundo-para-los-pacientes-andaluces-YC9260364; http://www.granadahoy.com/granada/botica-deja-negocio-rentable_0_967403363.html.

43 Véase: $h$ ttp://www.elmundo.es/andalucia/2016/12/27/586154edca474170468b4581.html.

${ }_{44}$ Así lo ha señalado YAGÜE SÁNCHEZ, J. R., Director del Departamento de Relaciones con las Comunidades Autónomas de Farmaindustria en su intervención en la Jornada "Modalidades de contratación para la adquisición de medicamentos: el debate sobre las subastas en Andalucía", celebrada en Málaga en junio de 2015 y organizada por la Asociación Andaluza de Derecho Sanitario. En ella señaló que Nueva Zelanda lleva realizando subastas desde 1997 y sólo queda un fabricante local de genéricos y son empresas extranjeras las que resultan adjudicatarias de prácticamente todas las subastas que se realizan en este país. Y en Alemania los resultados han sido parecidos, pues las subastas han traído consigo la deslocalización de la producción de genéricos hacia países de bajo
} nivel de costes. 
REALA. Nueva Época - N. ${ }^{\circ}$ 7, mayo 2017 - ISSN: 1989-8975 - DOI: 10.24965/reala.v0i7.10422 - [Págs. 126-142]

La subasta de medicamentos en Andalucía. Cuestiones controvertidas y perspectivas de futuro

Elsa Marina Álvarez González

de la autorización de comercialización de las presentaciones de los medicamentos y las empresas ofertantes de las presentaciones de los productos sanitarios que resulten finalmente seleccionadas deberán asumir el compromiso de garantizar su adecuado abastecimiento mediante declaración expresa al efecto.

Por tanto, podemos apreciar ciertas similitudes entre el sistema de precios seleccionados y el sistema de subastas andaluz. Ambos responden a una finalidad de contención del gasto farmacéutico y en ambos la Administración pública interviene en la determinación del precio de los medicamentos a través de un procedimiento abierto en el que participan los laboratorios farmacéuticos pero sin ningún margen de beneficio económico. En cambio, la principal diferencia radica en que el sistema de precios seleccionados no es excluyente, pues no limita la dispensación de los medicamentos de las agrupaciones homogéneas afectadas siempre que se ajusten al precio seleccionado, mientras que en las subastas andaluzas existe exclusividad del laboratorio farmacéutico para la fabricación del medicamento. Es cierto que la puesta en funcionamiento del sistema estatal requiere aún del correspondiente desarrollo reglamentario. En estos momentos, se encuentra en fase de información pública el proyecto de Real Decreto por el que se regula la financiación y fijación de precios de medicamentos y productos sanitarios y su inclusión en la prestación farmacéutica del Sistema Nacional de Salud, publicado en septiembre de 2015, y en el que se desarrolla el sistema de precios seleccionados. Tendremos que esperar si finalmente este proyecto ve la luz para poder analizar la efectividad de esta medida y para valorar si esta iniciativa reduce los problemas de abastecimiento y calidad que están teniendo las subastas, en cuyo caso, quedará por ver si la misma supone el fin del sistema de subasta de medicamentos andaluz. Lo que parece claro es que se trataría de una medida de racionalización homogénea para todo el territorio nacional sin distorsiones en el mercado único de medicamentos.

\section{BIBLIOGRAFÍA}

ALBA ROMERO, S., COMAS-MATA MIRA, C. y OLAY LORENZO, T. (coords.), Informe CEDEF sobre conocimiento práctico del genérico: su regulación, tecnología y calidad, Centro de Estudios de Derecho Europeo Farmacéutico, Madrid, 1998.

ALEGRE PÉREZ, E. y LASTRES GARCÍA, J. L., Normativa legal sobre las especialidades farmacéuticas publicitarias en España y su situación en el entorno europeo, Universidad Complutense de Madrid, Madrid, 2003.

ÁLVAREZ GONZÁLEZ, E. M., Régimen jurídico de la asistencia sanitaria pública: Sistema de prestaciones y coordinación sanitaria, Ed. Comares, 2007.

- "La ordenación farmacéutica en Andalucía", en PÉREZ MONGUIÓ, J. M. y FERNÁNDEZ RAMOS, S. (coords.), El derecho de salud pública y políticas sociales e igualdad de Andalucía, Ed. Instituto Andaluz de Administración Pública, 2016.

ALVARGONZALEZ FIGAREDO, M.: "Mercado interior y productos farmacéuticos: patentes y autorizaciones de comercialización", Noticias de la Unión Europea, núm. 148, 1997.

AMARILLA GUNDÍN, M. (coord.), Derecho Farmacéutico Actual, Aranzadi, Navarra, 2009.

BARRANCO VELA, R., (dir.), El acceso al medicamento. Retos jurídicos actuales, intervención pública y su vinculación al derecho a la salud, Ed. Comares, Granada, 2009.

BELTRÁN AGUIRRE, J. L., "Las competencias autonómicas sobre ordenación farmacéutica y la Ley del medicamento, Revista Jurídica de Navarra, núm. 11, 1991.

BOMBILLAR SÁENZ, F., Intervención administrativa y régimen jurídico del medicamento en la Unión Europea, Ed. UGR, 2010.

CENTENERA, J. I., "Importancia de los medicamentos genéricos en el control del gasto", en LÓPEZ GUZMÁN, J. (coord.), Medicamentos genéricos: una aproximación interdisciplinar, EUNSA, Pamplona, 2007.

MARTín MATEO, R., "La ordenación de las oficinas de farmacia", Revista Derecho y Salud, vol. 3, núm. 1, 1995, pág. 167.

MUÑOZ MACHADO, S., "Gasto farmacéutico y otras reformas del SNS", Revista Derecho y Salud, vol. 9, núm. 2, 2001.

RAZQUIN LIZARRAGA, J. A., "La competencia de las Comunidades Autónomas y de la Comunidad Foral de Navarra sobre ordenación farmacéutica", Revista Jurídica de Navarra, núm. 20, 1995, págs. 69 a 94.

TAMAYO LORENZO, P. A., "El gasto farmacéutico y la industria" en GIMENO ULLASTRES, J. A. (dir.), Economía de la Salud: Fundamentos, Ed. Díaz de Santos, 2013.

VIDA FERNÁNDEZ, J. "Precio y financiación de los medicamentos" en Curso básico de derecho farmacéutico: 100 cuestiones esenciales, Asociación Española de Derecho Farmacéutico, Madrid, 2005.

- "La prestación farmacéutica como subsistema prestacional sanitario" en MONEREO PÉREZ, J. L., Comentarios a la legislación reguladora de la sanidad en España. Régimen jurídico de la organización sanitaria, personal sanitario y prestaciones sanitarias, Ed. Comares, 2007. 